\title{
La representación de la historia a través del documental: el caso de El Efecto Nostradamus
}

\author{
Tania LóPEz GARcíA \\ Universidad de Burgos \\ tanialopezubu@gmail.com
}

\begin{abstract}
Resumen:
La serie, El Efecto Nostradamus, expone varias teorías sobre cómo acontecerá el fin del mundo. Especialmente hace hincapié en el año 2012 apoyándose a través de creencias de las culturas Maya, Hopi, cristiana e islamista, su cometido es reflejar en imágenes las suposiciones que nos conducirán al fin de los días.
\end{abstract}

Palabras clave: El Efecto Nostradamus; fin del mundo; Nostradamus; profecías

The representation of the history through de documentary format: the case of Nostradamus Effect.

\begin{abstract}
:
The television series Nostradamus Effect, shows many different theories about how would be the end of the world. It emphasized the year 2012 following the knowledge of several cultures as Mayans, Hopis, Christianity and Islamic fundamentalism, it tries to reflect on pictures the surmises that will lead us to the end of our days.
\end{abstract}

Key Words: Nostradamus Effect; the end of the world; Nostradamus; forecasts

Referencia normalizada:

López García, T. (2014): La representación de la historia a través del documental: el caso de El Efecto Nostradamus. Historia y Comunicación Social. Vol. 19. Núm. Especial Marzo. Págs. 491-497.

Sumario: 1. Introducción. 2. Metodología. 3. Las profecías. Una visión científica. 4. La narración. 5. Conclusiones. 6. Referencias bibliográficas. 7. Notas.

\section{Introducción}

A finales de 2009 y principios de 2010, el canal History Channel emitió por primera vez en Estados Unidos, la serie documental, El Efecto Nostradamus, un compendio de doce episodios dedicados a plasmar en imágenes cómo sería el fin del mundo según los argumentos proféticos de antiguas culturas y que han llegado a nuestros días. Uniendo los hechos fatalistas a los escritos de Michel de Nôtre-Dame, 
a quien consideran el vidente más famoso de la historia, se trata de reforzar la veracidad de los argumentos mayas, hopis, cristianos y musulmanes, entre otros, mostrándolos como la culminación de diferentes ideales en un mismo punto: la extinción. Es frecuente la asociación de estas ideas con hechos acaecidos y que han marcado un hito importante a nivel mundial, como es el caso del personaje de Adolf Hitler durante la Segunda Guerra Mundial, o los hechos en torno a la biografía de Lucía dos Santos en las afueras del pueblo de Fátima, sucesos en 1917 y donde se considera, dentro de la fe cristiana, que la Virgen María realizó tres revelaciones. En éste último caso la Virgen pronosticó el fin de la Primera Guerra Mundial, el inicio de la segunda... Sin embargo, no debemos olvidar la gran duda que acecha a la veracidad de estas revelaciones, en especial del tercer secreto que Juan Pablo II reveló el 13 de mayo del año 2000 pero que carece de la firma de la hermana Lucía y fomenta la idea de que es falso.

Otra tendencia dentro de la serie es la de hacer ver al espectador cómo una persona racional, estudiosa y avanzada a su época es capaz de creer, apreciar y desarrollar sus propias teorías acerca de qué le depara a la humanidad. Los episodios 3 y 8 nos exponen las investigaciones de Leonardo da Vinci y Sir Isaac Newton respectivamente. Finalmente, y en correspondencia con las creencias mayoritarias del target a quien está enfocada la serie documental, nos encontramos con varias personificaciones de la cultura cristiana, así como la recreación de momentos decisivos que son ejemplificados con atentados, catástrofes naturales y epidemias recientes. Es frecuente el poner una cara a seres ideológicos como Satán, los jinetes apocalípticos... la personificación nos conduce a poder representar su labor de destrucción en la tierra y genera un poder de sugestión que, acompañado de imágenes reales y otras digitales, tiene un atractivo mayor hacia la veracidad de la serie.

\section{Metodología}

Los doce episodios que conforman El Efecto Nostradamus se presentan en el siguiente orden: 1- Extinción 2012, 2- Los secretos de los siete sellos, 3- El Armagedón de Da Vinci, 4- El rapto y la tribulación, 5- Jeroglíficos del Juicio Final, 6- El juramento de sangre de Hitler, 7- Plan de batalla Armagedón, 8- El código del Apocalipsis, 9- El tercer Anticristo, 10- El ejército de Satanás, 11- Hijo de Nostradamus, 12- La profecía perdida de Fátima. El visionado de los mismos de forma analítica desde una perspectiva audiovisual y cultural nos permite una reflexión donde prima el simulacro de los posibles acontecimientos futuros. Es cierto que una de las hipótesis más defendidas en torno al año 2012 como el punto final de la historia cobra una gran importancia en la emisión original de la serie documental, sin embargo, pasada esta fecha, el escepticismo marca una pauta crítica donde desarrollamos el análisis. El carácter de esta investigación es, por tanto, desconfiada ante la parte científica que trata de mostrarse así como analítica en torno a la cuestión de la actitud del espectador frente a un mensaje codificado como documental. 
Nos atañe conocer las diferentes modalidades de los programas dramáticos y culturales en televisión como base para poder profundizar en una visión crítica ante lo que se muestra desde el punto de vista de la realización audiovisual. Entendemos el documental como la expresión de un aspecto real que se muestra en forma audiovisual donde en este caso tiene una doble función: centrarse en un acontecimiento puntual y definir el proceso que nos conduce a éste. El Efecto Nostradamus se ha mantenido en emisión a través de la cadena Xplora del grupo Atresmedia, quienes lo han presentado en su página Web como un documental histórico, si bien, llegados a este punto hemos de reconocer que la historia trata sobre el estudio del pasado y que, en este caso, tratamos constantemente sobre el futuro, a pesar de realizar una memoria histórica a través de personas en particular y culturas en general.

\section{Las profecías. Una visión científica}

El verismo es una característica que otorga realidad a una irrealidad provocando la coherencia en sí misma así como el carácter consecuente dentro de los hechos que la enmarcan. Una de las herramientas que favorecen la veracidad es la de mostrar escritos pertenecientes a diferentes culturas que existen y a los que tenemos acceso a día de hoy. Además, mezclar este elemento con hechos históricos, personas especializadas en el tema e imágenes que se corresponden con la realidad de situaciones catastróficas vividas a diario (como son los tifones, huracanes, la hambruna...) nos impulsa a considerar cierto el simulacro de lo real, el cual se retroalimenta con la veracidad y genera una pauta de asociación de ideas que limita el modo de entender lo que se expone. Dentro de los escritos proféticos en los que se centra la serie, vamos a analizar las dos que más peso cobran: las centurias de Nostradamus y la Biblia. Primero hemos de concretar que la base científica de El Efecto Nostradamus está entre las profecías y los testimonios orales de personas relacionadas con las mismas. Trabajamos con interpretaciones de interpretaciones donde se está transmitiendo un pensamiento moldeado en el que no se plantea que pueda haber un error comunicativo donde el emisor esté equivocado en su mensaje.

Nostradamus (1503-1566) fue un reconocido médico y profeta francés del Renacimiento que escribió sus visiones del futuro en cuartetas, las cuales se recogen en centurias. Un episodio en el que sus visiones toman una especial relevancia es en el de El juramento de sangre de Hitler donde partimos de la afirmación de Jeff Hall, quien describe al führer como un falso profeta cuyos ideales siguen vivos. El programa continúa explicando cómo algunos ocultistas actuales así como los textos bíblicos y las cuartetas de Nostradamus coinciden en encontrarse en una época satánica en lo referente al Tercer Reich. Entienden, que el vidente pudo ver el ascenso de Hitler al poder en uno de sus momentos de predicción en base a la Centuria IX, Cuarteta 90: Un capitán de la Gran Germania se rendirá por segurado socorro al rey de reyes de Panomia, cuya revuelta hará de sangre gran río. También se incide en la Centuria III, Cuarteta 35: De lo más profundo del occidente de Europa, de gente pobre, un joven 
niño nacerá que por su lengua seducirá a las masas. Entendiendo que ambas frases se encuentran desconexas y extraídas de un contexto determinado podemos tratar de interpretarlas en diferentes ámbitos y situaciones según se puedan amoldar a los mismos de una forma coherente. Si bien, ambas pueden enunciarse en ese contexto, es la palabra "Hister" (a la cual Nostradamus se refiere en ocasiones) la que más juego da dentro de la serie.

¿Puede un hombre profetizar ante el futuro? El punto de vista racional permite entender cómo es más sencillo amoldar una frase a un hecho histórico cuando ya ha sucedido y crear la imagen del visionario que nos advirtió y al que no escuchamos. ¿Por qué tiene tanto peso un escrito del sigo XVI que si esa era su interpretación pudo preverse? ¿Por qué tratamos como veraz algo tan efímero como una frase puntual de algo que no podemos conocer? ¿Es ético el uso de este recurso en la comunicación? Estas dudas se plantean desde la necesidad de desconfiar ante un argumento demasiado banal, apenas insertado desde una creencia hacia el ocultismo.

Aparentemente fácil de ver que la suposición no debe tratarse como información, planteamos ahora otro punto de vista con un arraigo mayor en nuestra cultura: los escritos bíblicos. ¿Qué sucede cuando el espectador está inmerso en una fe y esta se emplea como argumento? En prácticamente todos los episodios la doctrina cristiana asume una presencia, se hace referencia al Libro de las Revelaciones y a la cronología de los siete sellos. Los ejemplos que se exponen son bien conocidos por el espectador y se relacionan los cuatro primeros sellos con los jinetes del Apocalipsis, al igual que en el texto bíblico:

\begin{tabular}{|l|l|l|}
\hline SELLO & \multicolumn{1}{|c|}{ CORRESPONDE A } & \multicolumn{1}{c|}{ EJEMPLO } \\
\hline 1 & Jinete blanco & Hitler \\
\hline 2 & Jinete rojo & Holocausto nuclear \\
\hline 3 & Jinete negro & Crack de 2008 \\
\hline 4 & Jinete bayo & Calentamiento global \\
\hline
\end{tabular}

La idea de Hitler, un personaje histórico conocido a nivel mundial como representación de la victoria, el holocausto nuclear visto desde la posible amenaza de un autoritario jefe militar como el de Corea del Norte ejemplificando la guerra, la caída del mercado ocurrida en 2008 en Estados Unidos simulando la hambruna o el calentamiento global como la muerte, son todos ellos temas actuales, cercanos. Esta forma de relacionar conceptos muy distintos entre sí, con el poder psicológico de ser hechos reales, sugestiona al espectador. Curiosamente, no se tratan ni el quinto ni el sexto sello y se pasa directamente al séptimo que dice que se producirá un silencio sepulcral donde Dios ofrecerá una tregua a la humanidad. La apertura del último sello se relaciona con el posible choque de un asteroide, una muestra de la mezcla de la Biblia Kolbrin, con las enseñanzas cristianas que encaja dentro de la serie con el capítulo 5: Jeroglíficos del juicio final.

Otro punto donde la religión cristiana se torna determinante es en la vida de Leonardo da Vinci e Isaac Newton. Da Vinci es reflejado como un artista que pudo llegar a desarrollar teorías apocalípticas en sus obras, tres de sus obras; La Mona 
Lisa, La Virgen con el niño Jesús y Santa Ana, y San Juan Bautista, se consideran respectivamente la amenaza de un cataclismo geológico, la humanidad al borde de la aniquilación y como un aviso de que algo inexplicable se acerca. ¿Por qué cobra tanta importancia esta opinión sobre su arte si el mismo ya dijo que era un argumento ilógico? Newton es presentado como un estudioso de la biblia que no pudo desvelar sus descubrimientos acerca del fin del mundo en su época, como si ahora sí pudiesen ser revelados porque tenemos las herramientas necesarias para proceder a ello. Para el científico, 2060 es la fecha en la que el mundo llegará a su fin, parte del año 800 d.C., cuando el Papa coronó rey a Carlomagno, emperador de lo que acabaría siendo el Sacro Imperio Romano. A esta fecha, añade el tiempo que el profeta Daniel dice, en la Biblia, que pasará para que llegue el fin de los días: un tiempo, dos tiempos y medio tiempo, entendiendo por 1 tiempo, un año. Nos encontraríamos con: 1 tiempo (360 días), 2 tiempos (720 días) y medio tiempo (180 días), cifras que Newton interpreta como años y los suma al año 800. ¿Es ésta la forma de evadir la responsabilidad documental si en 2012 no acaba el mundo? ¿Comprende esto la refutación del resto del material de la serie? ¿Si no llegó el fin del mundo el 21 de diciembre de 2012, debemos seguir considerando las teorías que se presentan como proféticas?

\section{La narración}

Como ya se ha indicado, la narración audiovisual se asemeja a la del documental, sin embargo, en este apartado nos interesa más poder observar otros parámetros como el modo en que son presentadas las culturas, la relevancia de las mismas, qué hechos reales son destacados y cómo nos influyen para determinar si es o no posible que el mundo acabe con la confluencia de catástrofes que conocemos de forma aislada.

La civilización Maya, los indios Hopi, el cristianismo, el judaísmo, el islamismo y la cultura egipcia se representan como fuentes de conocimiento puras a las que hemos dado la espalda o que se encuentran fuera de las preocupaciones diarias de la vida real. Se muestran como un referente con unos conocimientos que somos incapaces de comprender por no vivir de la misma forma que ellos. Algunos interlocutores afirman en los episodios que los Mayas tenían un conocimiento asombroso sobre ciencia, arte, astronomía... y que eran capaces de observar la naturaleza de un modo que nosotros no podemos y su calendario acaba en el año 2012. Los indios Hopi, con su sistema de división del tiempo, abrían determinado que nuestra sociedad se encuentra en la cúspide del mismo, en el cuarto mundo, donde no hay continuación. Los antiguos hindúes entienden que la vida en el universo sucede en ciclos, los cuales se dividen en cuatro edades llamadas yugas, la humanidad nace con la virtud, y acaba con la corrupción. Para ellos vivimos en la edad final, la Kali yuga (del cuarto mundo), la cual empezó en el 3102 a.C. y nos conduciría al final de nuestros días porque la humanidad se consumirá a sí misma hasta que un cataclismo final lo aniquile todo. 
La cultura egipcia se estudia en un episodio a parte en Jeroglificos del juicio final, donde partiendo de los conocimientos arquitectónicos de esta antigua civilización se deriva a una interpretación cronológica según el diseño y la métrica de la pirámide de Guiza donde se llegaría a un punto final de 11 de septiembre de 2001. Después se desarrollan dos teorías diferentes: que la tierra sufra un cambio polar (opción descartada por los científicos) o que se cumpla la Profecía de Orión, esta última trata de que El Destructor, un misterioso cuerpo celeste, pasara tan cerca de la tierra que sin la necesidad de tocarla causará su destrucción. Tras aceptar como posiblemente válida la segunda opción, lejos de lo científico se especula que la esfinge situada cerca de la Gran Pirámide contiene el secreto de la salvación de la tierra o que si se encontrara la cúspide de la pirámide podría desprender una gran fuerza que desplace a El Destructor y salve al planeta y a la humanidad de su fin.

El papel de las culturas no es más que el de buscar fuentes proféticas que afiancen los escritos de Nostradamus y den un juego a parte a los extractos del Libro de las Revelaciones. Es difícil enfrentarse a pensamientos y sociedades tan antiguas y el espectador no tiene por qué tener un conocimiento profundo sobre ellas. Es muy importante la influencia de los Mayas, ya que antes de 2012 proliferaron multitud de libros relacionados con el fin del mundo y muchos oradores se hicieron eco y ganaron protagonismo a raíz del calendario que llegaba a su fin (muchos de ellos han dejado de aparecer en televisión y no se han pronunciado ante la continuación de la vida en la tierra mientras que otros han declarado estar arrepentidos de su conducta profética). Los indios Hopi tienen unas ideas que conectan a la perfección con los Mayas: se asemejan en sus sistemas de división del tiempo, inician sus calendarios casi a la par, ambos entienden que hay un fin de la humanidad. Se presentan civilizaciones que se apoyan entre sí, y de la Biblia se trata en mayor medida el Apocalipsis, el único libro que se acepta de forma general como profético y, a su vez, el más complejo de interpretar por la simbología que contiene. Poniendo en duda que la cuestión semiótica quede resuelta en los episodios, sólo podemos ver El Efecto Nostradamus como un acercamiento al fin del mundo que les apetece ilustrar, dejando de lado la parte objetiva y los argumentos divergentes.

\section{Conclusiones}

Tras el breve análisis vamos a concretar tres puntos. En primer lugar: la temporalidad. Este factor es clave para conocer enfrentarnos a las profecías que a día de hoy recopilamos y además porque sabemos que el mundo no concluyó en 2012, siendo así derogadas todos los argumentos presentados en la serie que confiaban en la veracidad de estas propuestas históricas. El programa está postulado hacia la veracidad de los argumentos que se presentan y que, tal vez, por su carácter acientífico, deberían ser mostrados bajo un tamiz de incredulidad y objetividad. Podemos decir que la información presentada está sesgada bajo los intereses propios y carece de un cono- 
cimiento cultural amplio, variado y versátil que pueda mostrar una cara opuesta a la realidad mediatizada.

En segundo lugar, Nostradamus se presenta como la figura clave pero cuyos escritos están totalmente fuera de un contexto continuado y lógico, de su amplia obra profética, hay muchos errores, teorías nunca acontecidas y una gran plasticidad dentro de cada cuarteta. Podemos extraer sus revelaciones de forma individual y hacerlas coherentes en varios contextos, lo que nos permite una gran flexibilidad en la interpretación de las mismas.

Finalmente, hay que pensar cómo el espectador recibe esta información, cómo está influido por los factores geográficos a los hechos que se ejemplifican en las imágenes reales, en especial en la sociedad estadounidense: 11-S, huracán Katrina, crack bursátil, virus H1N1... si descontextualizamos todas estas situaciones para unirlas a un fin común creamos un gran poder de sugestión. Asombra por qué se dedica tan poco tiempo a teorías que no podemos asegurar a día de hoy, como el cambio polar de la tierra, y sin embargo, cómo aquellas que son difícilmente creíbles y parten de suposiciones, se hacen con una presencia mayor: la llegada de El Destructor a la Tierra o el fin del mundo por el fin de un calendario que nadie sabe por qué concluyó en esa fecha.

¿Dónde queda el valor ético de la información presentada? ¿Hasta dónde se permite jugar con los programas dramáticos y culturales? ¿Hasta dónde llega la credibilidad del espectador? ¿Forma parte el futuro de la historia? Estas cuestiones nos abren a la capacidad de discurrir ante una serie documental disfrazada que no cuenta ni con profesionales del medio ni de la materia. Tratamos pues de iniciar una reflexión ante cómo se representa la historia en función de los fines comerciales y de audiencia que un canal televisivo pueda tener, cómo de importantes son los gustos del target seleccionado para hacer llegar nuestro mensaje y entender que la falta de información objetiva trunca el mensaje y provoca un error comunicativo.

\section{Bibliografía}

BARROSO, J. (2008). Realización audiovisual. Síntesis: Madrid.

ECO, U. (1997). Interpretación y sobreinterpretación. Cambridge University Press: Madrid.

FERNANDEZ DÍEZ, F.; MARTÍNEZ ABADÍA, J. (2011). Manual básico de lenguaje y narrativa audiovisual. Paidós Comunicación: Madrid.

GRANDI, R. (2001). Texto y contexto en los medios de comunicación. Bosch: Barcelona. 